\title{
Laughter A Stress Buster Remedy Among Elderly People Living In The Old Age Homes.
}

\author{
Mrs, Dalbir Kaur \\ (Lecturer, Mental health nursing department LLRINE, GDH, JALANDHAR, PUNJAB, INDIA)
}

\begin{abstract}
:
Aim: To give easy remedy "Laughing" Skill to reduce the stress.

Objectives: Old age is inevitable. But, it is possible to keep the mind agile and active to a great extent. The relation between age and stress is a close one. Aging may simply wear out the systems in the brain that respond to stress, so that they become inefficient.

Methodology: A Quasi experimental study (non equivalent control group design) Study was conducted in old age homes of Jalandhar District on 60 samples. Purposive sampling technique was employed and two groups were formed, one control and other experiment. Then pre test was conducted through Semi-structured Interview Schedule, Laughing sessions were given to the Experimental group for two weeks (20-25 minutes). After two weeks post test was conducted on both groups.

Result: Experimental group mean of level of stress score was (10.86) in pre test and (4.8) in post test, significant at $p<0.05$ level. On the other hand, in control group mean of level of stress score was (11.533) in pre test and (12.133) in post test and non significant at $p<0.05$ level. In the pre test of experimental group 1(3.3\%), 0 and $29(96.66 \%)$ subjects fall in mild, moderate and severe level of stress respectively. In post test number of person increased in moderate $16(53.33 \%)$, mild $9(30 \%)$, level of stress. Only $5(16.66 \%)$ remained in the severe level of stress.
\end{abstract}

Conclusion: It was concluded that the result of the study shows that laughter has a distinguishable effect on level of stress.

\section{Introduction}

Old age is inevitable. Nobody can stop the aging process of the human body. But, it is possible to keep the mind agile and active to a great extent. Age is of two types. One kind of age is the age of the physical body and the other is the age of the mental body. The physical body never stops ageing. The mind however can be kept young and active by taking part in such kind of activities. So, Ageing is one of the crucial issues attracting the attention of public health personnel.

Ageing is a natural process. In words of Seneca; "Old age is an incurable disease", but recently they commented it as "we do not heal old age but protect it; promote it; extend it". Ageing can be defined as the life long process of progressive change in biological, psychological and social structure of a person. ${ }^{(2)}$

In India there are 76 million elderly people constituting $7.7 \%$ of the total population. ${ }^{(3)}$ With current demographic trends it is estimated to reach $21 \%$ by the year $2050 .{ }^{(4)}$ Ideally, aged people should live in comfortable and friendly environment that only family can provide. The accommodation and care of frail and physically dependent elderly has become a complex issue now-a-days in the face of smaller family size, increasing number of women in the workforce and migration of productive younger population. Hence, the need for institutional facilities arises. Institutional care is no longer considered unacceptable for an older person, but, is seen as an alternative for families. ${ }^{(5)}$

In Punjab, Shifting of elderly in old age homes is seen due to family circumstances, misunderstanding with the family, generation gap, and conflicts with the children, loneliness, empty nest, and death of spouse, financial constraint, disability, chronic diseases and many more. This acts as a stressor and give birth too many diseases as well as increase intensity of chronic diseases of sufferer.

Stress is a term that is widely used in everyday life with most people having some appreciation about its meaning. Prolonged stress and ineffective coping interfere with the meeting of basic needs and can affect physical and mental health. One cannot deny it as a stressor for old age.

Old age is the time when the people realize their loneliness. The stressors of old age such as loss of skill and competencies develop early in life, adjustment to retirement and loss of income, coping with change in role function and social life, diminished quantity and quality of relationships and coping with loss in turn make the elderly feel a little insecure and lost. So, when the family and social life is disrupted, then the elderly feel a sense of loss and they are put at a level of discomfort and leads to a slow build up of stress. ${ }^{6}$ 
Moreover, old age people are subjected to difficult degree of stress from their environment, which affect their physical and mental health. So, the laughter is an instant stress buster, which helps to reduce the risk factors. ${ }^{7}$. Thus, old age and stress go hand in hand.

As Psychiatrist Robert Holden states, laughing produces happy chemicals in the body called endorphins which work in the brain to give an overall feeling of well-being. Laughing, however, does not have to be genuine. Fake laughter will also cause the body to respond as if the laughter is real. ${ }^{8}$

Laughter is one of the body's safety valves, a counter balance to Tension. When tension released, the elevated levels of the body's Stress hormones drop back to normal, thus allowing our Immune Systems to function more effectively. Sigmund Freud summarized in his theory that laughter therapy release tension and "psychic energy" it is coping mechanism for when one is upset, angry or sad. 15 minutes of laugh is equals to the benefit of two hour sleep, 15 minutes laugh adds two days life span. It stimulates the brain, respiratory, nervous, hormonal and muscular system. Many researches evidenced that laugh increase the secretion of serotonin in brain which is essential for the uplift of mood. ${ }^{9}$

Laughter provides good exercise to organs and enhances blood supply. ${ }^{10}$

It releases endorphins, natural opiates that stimulate feelings of caring and forgiveness. It increases the levels of immunoglobulin A that is the first line defenses against viral infections such as cough and cold and also fight with the cancer cells. It provides an excellent cardio and mind body workout. it causes an "internal jogging" that massages and promote the circulation to the digestive and lymphatic system and remove the toxins from the body. It improves the social skills and emotional intelligence. Laughter is preventive and therapeutic. ${ }^{10,11}$

The relation between age and stress is a close one. According to researchers, long term exposure to stress leads to health problems in old age. People who take more stress are liable to feel more tired and sick than people who lead a stress free life. ${ }^{12}$

As people age, achieving a relaxation response after a stressful event becomes more difficult. Aging may simply wear out the systems in the brain that respond to stress, so that they become inefficient. The elderly, too, are very often exposed to major stressors such as medical problems, the loss of a spouse and friends, a change in a living situation, and financial worries, lack of bonding, loneliness due to "empty nest", physical disorders, immobility due to Sedentary lifestyle, illness and lack of physical exercise cause stiffness of limbs and muscles, Senile Dementia ecsectra. No one is immune to stress, however, and it may simply go unnoticed in the very young and old. ${ }^{13}$

India is a developing country, industrialization and urbanization resulting in social structure of country. Generation gap and technology also play vital role in the change in the relationships. In turn, family bond is becoming loosened day by day. The elderly are neglected, feel as a burden on the family, useless, narrow minded in the families. Similarly, in the Punjab, elderly are forcibly put in to old age homes or expelled from the home, abused by the children. Therefore, elderly are more vulnerable to the effects of stress and stress related diseases.

Moreover, life expectancy has increased, because of advancement in science and medicine. The trends of population are a demanding challenge for the developing country, India. It is need of hour that there should be adequate provision of promotive, preventive, therapeutic, and advance rehabilitative services. So, there are many priorities that push the interest to provide easy and economic remedies to them to live healthy and deal with change of scenario. Thus the laughter is one of the easy, cost effective, less time consuming remedy to experience healthy aging as well as to keep away from many diseases related to stress both physical and psychological. ${ }^{3}$ 


\section{Methodology}

\section{RESEARCH DESIGN}

Quasi-experimental (non equivalent control group pre test post test design)

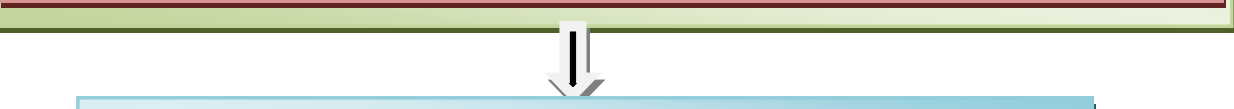

TARGET POPULATION

(Elderly residing in selected old age homes)
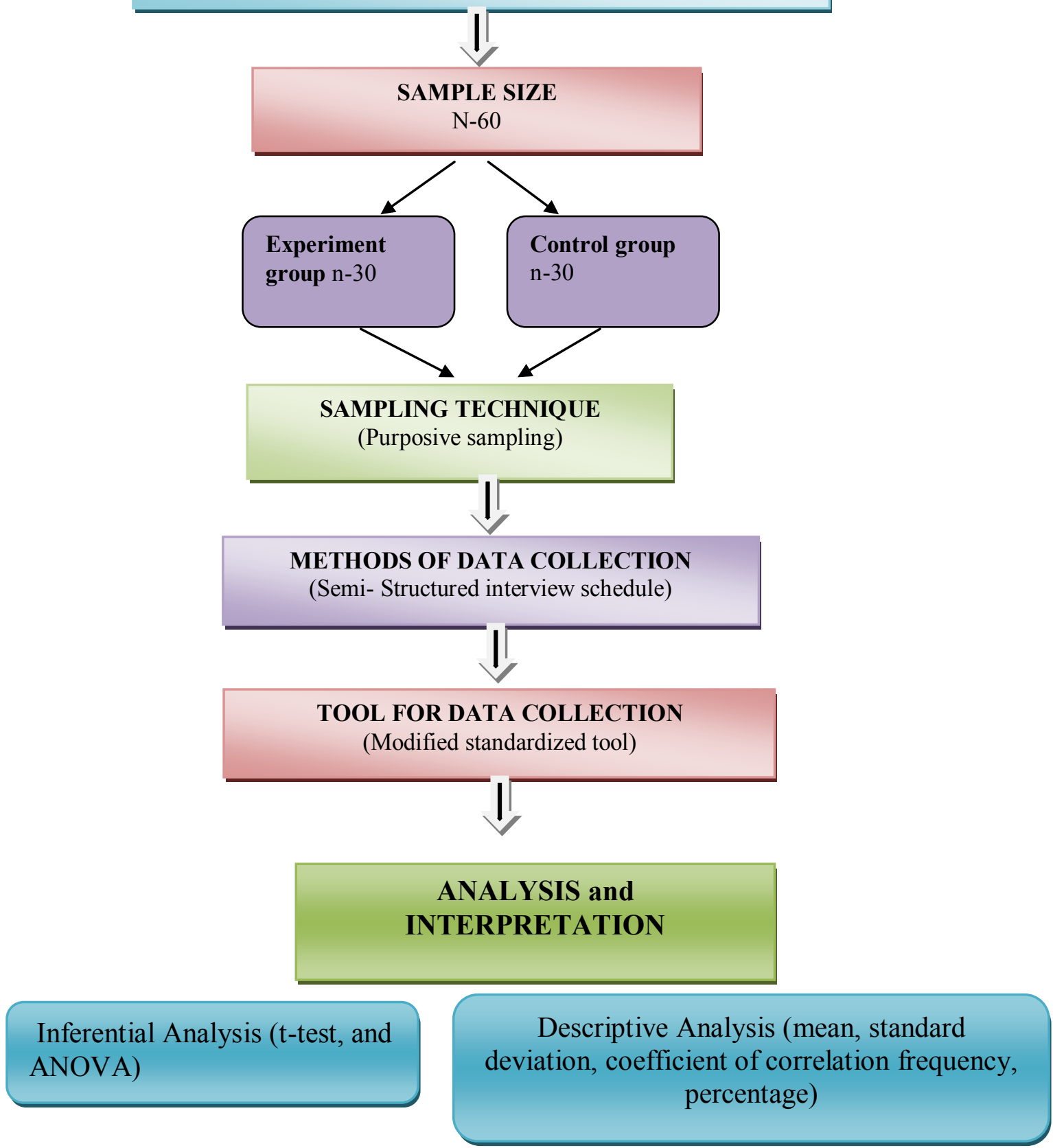

Figure no. 1 Schematic diagram of research methodology 
A Quasi experimental (Non equivalent control group pretest and post test design) was prepared to develop a plan of strategy that would guide for the collection and analysis of the data.

$$
\begin{array}{ccc}
\mathrm{O}_{1} & \mathrm{X} & \mathrm{O}_{2} \\
\mathrm{O}_{1} & - & \mathrm{O}_{2}
\end{array}
$$

Research setting is Apahaj ashram, Red Cross senior citizen home, Kundan virdh ashram of Jalandhar district, Punjab and the target population includes elderly residing in selected old age homes of Jalandhar district, Punjab. A total of 60 elderly people (30 in experiment group and 30 in control group) residing in Apahaj ashram, Red Cross senior citizen home, Kundan virdh ashram of Jalandhar district, Punjab. Purposive sampling technique was employed to collect data. Inclusion and exclusion criteria was followed.

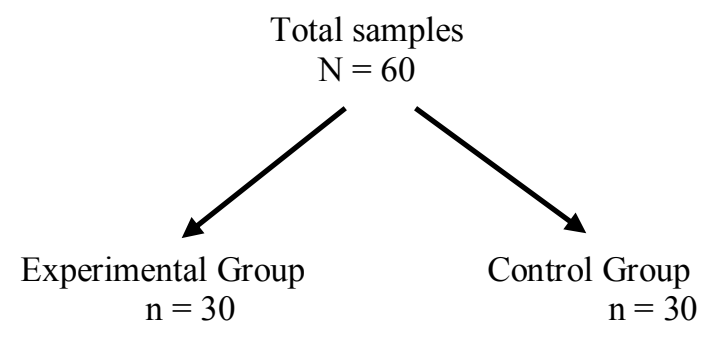

\section{Selection and development of tool}

Level of stress assessment checklist was selected to conduct the study. Tool was employed through semi- structured interview schedule. The tool is divided in three sections: Section-1: Sample characteristics, Section-2: This include checklist of 20 statements. Section 3- This part consisted of laughing which is planned to give daily in the morning for two weeks for 20-25 minute. Tool validity and reliability of tool was established (0.98).

\section{Criterion Measurement}

Total Score-20

$\begin{array}{lc}\text { Level of Stress } & \text { Scores } \\ \text { Mild } & 0-3 \\ \text { Moderate } & 4-6 \\ \text { Severe (Extremely vulnerable } & 7 \text { and more }\end{array}$

and at risk of stress related

Illnesses).

\section{Results:}

The table- 1 depicts the comparison of experimental and control group level of stress before and after intervention. It shows that experimental group sample level of stress reduced remarkably after the intervention. It is observed that in the pre test of experiment group 1(3.3\%), 0 and $29(96.66 \%)$ subjects fall in mild, moderate and severe level of stress respectively. Whereas, the number of elderly people has increased in moderate [16 $(53.33 \%)]$ level of stress and mild [ $9(30 \%)]$ level of stress as compared to the pre test of experimental group. Only $5(16.66 \%)$ elderly people of sample remained in the severe level of stress after the intervention (laughing). while in control of the study $1(3.3 \%), 2(6.6 \%)$ and $27(90 \%)$ sample of elderly people suffer from mild, moderate and severe level of stress in the pre test and level of stress increased after two weeks of the study (Post test). The result shows that shifting of sample in various level of stress in experimental group is only due to the laughing as compared to the control of the study. Thus, results has evidenced that laughing is effective to reduce the level of stress among elderly people living in old age homes of Jalandhar district, Punjab.

TABLE 1

Frequency and Percentage distribution of elderly people level of stress (Experiment and Control group)

\begin{tabular}{|c|c|c|c|c|}
\hline \multirow{3}{*}{ Level of stress (score) } & \multicolumn{4}{|c|}{ N-60 } \\
\hline & Experiment & it Group Pre test & Contr & rol Group \\
\hline & $\begin{array}{l}\text { Post test } \\
\mathrm{n} \\
(\%)\end{array}$ & $\begin{array}{r}n \\
(\%)\end{array}$ & $\begin{array}{c}\text { Pre test } \\
n \\
(\%)\end{array}$ & $\begin{array}{c}\text { Post test } \\
\mathrm{n} \\
(\%)\end{array}$ \\
\hline Mild & $1(3.3)$ & $9(30)$ & $1(3.3)$ & - \\
\hline Moderate (4-7) & 0 & $16(53.33)$ & $2(6.6)$ & $1(3.33)$ \\
\hline Severe ( 7 and more) & $29(96.66)$ & $5(16.66)$ & $27(90) 2$ & $29(96.66)$ \\
\hline
\end{tabular}
before and after intervention. 


\section{Maximum score $=\mathbf{2 0}$}

Minimum score $=0$

Note: level of streess should be less after laughing session.

TABLE 2

Comparison of mean of level of stress among elderly people in both experiment and control group of the study

Level of stress N-60

\begin{tabular}{lllllllll}
\hline & Pre test & \multicolumn{7}{c}{ Post test } \\
Group & $\mathbf{n}$ & Mean & SD & n & Mean & SD & 't' value & df \\
\hline Experiment & 30 & 10.86 & 3.363 & 30 & 4.8 & 1.91 & $8.58^{*}$ & 29 \\
& & & & & & & & \\
Control & 30 & 11.533 & 3.3 & 30 & 12.133 & 2.654 & $0.776 \mathrm{NS}$ & 29 \\
& & & & & & df & 't' \\
& df & 't & & & & 58 & $12.28^{*}$ \\
\hline
\end{tabular}

Maximum score $=\mathbf{2 0}$

Minimum score $=0$

\section{NS = non significant \\ * significant $\mathbf{p}<0.05$ \\ df $=$ degree of freedom}

Table-2 depicts the experimental group mean level of stress score was (10.86) and (4.8) in pre test and post test respectively. The difference between pre test and post test mean level of stress score was (6.06) significant at $p<0.05$ level. In control group mean level of stress score was (11.533) in pre test and (12.133) in post test. The difference between pre test and post test mean level of stress score was (-0.6) non significant at $\mathrm{p}<0.05$ level. The difference between mean level of stress score in control group and experiment group post test and post test was significant at $\mathrm{p}<0.05$ level. The mean level of stress score of control group and experimental group pre test and pre test was non significant at $p<0.05$ level. From the above it is found that pre test and post test of control group are independent. No change occurs in level of stress. Post test of control group and post test of experimental group show that, that are related in such a way that laughing effect the level of stress as ,tee $12.28>1.960$ at $5 \%$ level of significance.

So, research hypothesis $\mathrm{H}_{1}$ is accepted and null hypothesis $\mathrm{H}_{0}$ was rejected. The experiment group has shown a dramatic change in the level of stress as compared to the control of the study that indicates that laughing is effective stress buster.

\section{Major Findings}

- In experiment group maximum (46.67\%) elderly people were in age group 55-65 and minimum $(23.33 \%)$ in 76 and above year old. In control group. In control group maximum $(46.67 \%)$ in age group of 66-75 and rest of subject were equally distributed in the other groups of age.

- Both groups gender distribution was approximately same that is $70 \%$ males and $30 \%$ females.

- In both group majority of the sample belonged to Hindu (83.34\%) and Sikh (56.67\%), minimum belongs to Christian (3.33\%), (10\%), rest of the elderly people belongs to Sikh $(13.33 \%),(33.33 \%)$ religion respectively. No one belong to the Muslim religion.

- Experimental and control group sample, majority were educated up to higher secondary that is $(63.34 \%)$ and $(56.67 \%)$, minimum educated up to graduation $(10 \%)$ and $(20 \%)$ rest of the sample were illiterate $(26.66 \%)$ and $(23.33 \%)$ in order mentioned.

- Experimental and control group maximum of the sample marital status was married (66.7\%) and $(46.67 \%)$, widow/widower $(23.33 \%)$ and $(36.67 \%)$ in respective group. Both groups had equal percentage of unmarried sample $(10 \%)$ and only control group have divorced/separated (6.66\%) elderly people.

- $(80 \%)$ sample of study was from the nuclear family and rest $(20 \%)$ from the joint family in experimental group. In control group (66.33\%) from the nuclear family and remaining $(36.67 \%)$ was from the joint family. No one belong to the extended family in the both groups.

- With respect to the duration of stay in old age home of experimental group below one year and 1-3 year was $(26.66 \%)$ equal and remaining elderly people were staying in old age home since 3 years and more. in control group majority of the elderly people were living in the old age home from 1-3 years of period, $(33.33 \%)$ stay were below one year and rest of the elderly people staying in the old age home was 3 years and above $(20 \%)$. 
- In experimental group of (70\%) of sample was dependent on the old age home for economic support and $(23.33 \%)$ was pensioner. But minimal $(6.67 \%)$ numbers of elderly people were getting family support for finance.

- It was found that no socio demographic variables were significant associated with the level of stress.

- Experimental group of the study sample level of stress reduced remarkably after the intervention. It is observed that in the pre test of experiment group 1(3.3\%), 0 and $29(96.66 \%)$ subjects fall in mild, moderate and severe level of stress respectively. in the pre test of control of the study was $1(3.3 \%)$, $2(6.6 \%)$ and $27(90 \%)$ mild, moderate and severe level of stress respectively.

- In the post test of the study there was no decrease in the level of stress in the control of the study sample of elderly people that was $1(6.6 \%)$ level of stress was moderate and $29(96.66 \%)$ severe.

- Whereas, the number of elderly people has increased in moderate $16(53.33 \%)$ level of stress and mild $9(30 \%)$ level of stress as compared to the pre test of experiment group after the laughing sessions of 20-25 minutes daily in the morning. Only 5 (16.66\%) elderly people of sample remained in the severe level of stress after the intervention (laughing).

- It was found that the experimental group mean level of stress score was (10.86) in pre test and (4.8) in post test. The difference between pre test and post test level of stress score was significant at $p<0.05$ level. On the other hand, in control group mean level of stress score was (11.533) in pre test and (12.133) in post test. The difference between pre test and post test level of stress score was non significant at $\mathrm{p}<0.05$ level.

- The mean score level of stress of control group (11.533) and experimental group (4.8) pre test and post test was non significant at $\mathrm{p}<0.05$ level.

- From the above it is found that pre test and post test of control group are independent. Post test of control group and post test of experimental group show that that are related in such a way that laughing effect the level of stress as , t" $^{\text {" }} 12.28>1.960$ at $5 \%$ level of significance.

\section{Discussion}

The objectives of the study were: Objective I-To assess the level of stress among elderly people living in old age homes before the intervention in experimental and control group. Objective II-To assess the level of stress among elderly people living in old age homes after the intervention in experimental and control group. Objective III-To compare the stress level of subjects before and after the intervention in experimental and control group. The result of present study according to the first two objectives shows that experimental group of the study sample level of stress reduced remarkably after the intervention. It is observed that in the pre test of experiment group 1(3.3\%), 0 and 29(96.66\%) subjects fall in mild, moderate and severe level of stress respectively. in the pre test of control of the study was $1(3.3 \%), 2(6.6 \%)$ and $27(90 \%)$ mild, moderate and severe level of stress respectively. In the post test of the study there was no decrease in the level of stress among control group. Even the control of the study sample of elderly people level of stress increased after two weeks of the study, in Post test the level of stress was 1(6.6\%) moderate and 29(96.66\%) severe. Whereas, the number of elderly people increased in moderate(16(53.33\%)) level of stress and mild $9(30 \%)$ level of stress as compared to the pre test of experiment group after the laughing sessions of 20-25 minutes daily in the morning for 15 days. Only 5(16.66\%) elderly people of sample remained in the severe level of stress after the intervention (laughing). The result shows that shifting of sample in various level of stress in experiment group is only due to the laughing as compared to the control of the study.

According to the present study, third objective was to compare the pre test and post test of both groups of study. It was found that the experimental group mean of level of stress score was (10.86) in pre test and (4.8) in post test. The difference between pre test and post test level of stress score was significant at $p<0.05$ level. On the other hand, in control group mean of level of stress score was (11.533) in pre test and (12.133) in post test. The difference between pre test and post test level of stress score was non significant at $p<0.05$ level. The difference between mean of post test and post test of level of stress score in control group(12.133) and experiment (4.8) group post test, was significant at $\mathrm{p}<0.05$ level. The mean score of level of stress of control group (11.533) and experimental group (4.8) pre test and post test was non significant at $\mathrm{p}<0.05$ level. From the above it is found that pre test and post test of control group are independent. No change occurs in the level of stress. Post test of control group and post test of experimental group show that that are related in such a way that laughing effect the level of stress as , "t" $12.28>1.960$ at $5 \%$ level of significance. Fourth objective of the present study, was to find out the association of stress and laughing with selected socio-demographic variables such as age, gender, education, religion, marital status, type of family, duration of stay in old age home and economic support was statistically non significant except gender in the pre test of experimental group. It was found significant association with the laughing at the level of $5 \%$ that is $2.52>1.960$, means females have more level of stress than male of the study sample. So, the crux of the matter is that research hypothesis H1 is accepted and null hypothesis $\mathrm{H} 0$ was rejected. The experiment group has shown a dramatic change in the level of stress as 
compared to the control of the study that indicate that laughing is effective to reduce the level of stress among elderly people living in selected old age homes of Jalandhar district, Punjab.

Similarly, Shahidi. et al. (2010) conducted a study on Laughter Yoga versus group exercise program in elderly depressed women: a randomized controlled trial. He assessed effectiveness of laughter with geriatric depression score (GDS), Researchers has found that there was Changes in depression scores that individuals in both laughter therapy and exercise therapy group showed significant improvement in their GDS scores $(p<0.001$ for laughter therapy vs. control group and $\mathrm{p}<0.01$ for exercise therapy vs. control group). There was no significant difference between two experimental groups $\left(\mathrm{p}^{1 / 40.4)}\right.$. To control the effect of pre-test on post-test scores 75

Researchers used analysis of covariance (ANCOVA) and showed significant difference among the means of the three groups. In the same study researcher also observed the effect of laughing on the changes in life satisfaction scores. Only subjects in Laughter Yoga group showed significant improvement in their Life Satisfaction Scale scores compared with controls ( $p<0.001$ after Bonferronies correction). There was no significant difference in the Life Satisfaction Scale scores between exercise therapy and control group $\left(\mathrm{p}^{1 / 40.1)}\right.$. Again ANCOVA was performed to control for pre-test scores effect and showed significant difference between means of the three groups. It resulted in improvement of both depression and life satisfaction with laughing and also as compared to exercise therapy. According to the researchers this study was the first, to our knowledge, that showed the efficacy of Laughter Yoga in a mental illness.

\section{Conclusion:}

The result shows that decrease in the level of stress that is shifting of sample in various level of stress (from severe to moderate to mild) of experiment group is only due to the laughing as compared to the control of the study.

\section{References:}

[1]. Park K. Essentials of Community Health Nursing. $3^{\text {rd }}$ ed. M/s Banardsidas Bhanot; 2002 Jabalpur ; 656-58

[2]. Sachdev Y R. 1988. Winning over the old age or the ageing process. Proceedings of the International Conference in Geriatric Medicine and Gerontology. New Delhi, India. the Geriatric Society of India.

[3]. Neki N.S. Geriatric update caring for elderly.......proceedings of the $8^{\text {th }}$ international conference on geriatric care; Amritsar, Punjab; 2011; Geriatric society of India. P. 209-12,184-85, 226-33.

[4]. Kulkarni AP, Baride JP. 2002. Care of special groups. Text book of Community Medicine 2nd ed ; 522-524

[5]. Sharma AL. Geriatrics- A challenge for the twenty first century. Indian Journal Public Health 2003;47:18.

[6]. Laughter is the Best Medicine. [online].2006, October 11. [cited10:59 2012 January 23] available from:URL: http://www.writework.c

[7]. Laughter is the Best Medicine. [online].2006 October 11.[cited10:59, 2012 Jan 23] ; available from:URL: http://www.writework.c

[8]. Dr. Chandershekar C.R. effects of stress on body and mind - a book on stress induced physical and psychological ailments and remedies 1st ed. 2009; Karnataka: amateur connsellors' forum. 2009. p. 79-81

[9]. James E. Birren, editors. Humour as therapy encyclopedia of gerontology age, aging, and the aged vol. 1 and 2;academic press; vol 1\&2. p. 727-56.

[10]. Stress and stress related diseases in old age [online]. 2011 [cited on 2011 dec 22];available from:URL:http://www.umm.edu/patiented/articles/who at risk chronic stress or stressrelated_diseases_000031_6.htm\#ixzz1nJcIKR71

[11]. Costa, P.T., MCCRAE,R.R. Psychological stress coping in old age. Handbook of stress: theoretical and clinical aspects. Edited by Goldberger and S.briznitz. Newyork:free press 1993;p.403-12

[12]. Stress and stress related diseases in old age [online]. 2011 [cited on 2011 dec 22];available from:URL:http://www.umm.edu/patiented/articles/who at risk chronic stress or stressrelated diseases $000031 \quad 6 . h t m \#$ ixzzlnJcIKR71

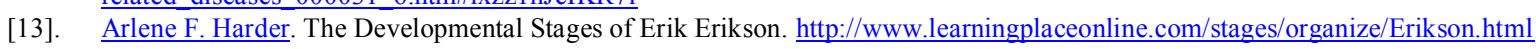

